\title{
Early prenatal detection of double outlet right ventricle by echocardiography
}

\author{
PATRICIA A STEWART, * JURIY W WLADIMIROFF, ^ ANTON E BECKER \\ From the ${ }^{*}$ Department of Obstetrics and Gynaecology, University Hospital Dijkzigt Rotterdam, and the $\nmid$ Department \\ of Pathology, University of Amsterdam Academic Medical Centre, The Netherlands
}

SUMMARY A double outlet right ventricle with subpulmonary ventricular septal defect and right sided hypoplastic aorta was diagnosed in a 22 week fetus of a mother with diabetes mellitus. Elective termination of pregnancy was carried out and the echocardiographic findings were confirmed. Early prenatal detection of congenital heart disease may allow elective termination of pregnancy when the fetus has severe defects.

The first description of double outlet right ventricle was provided in 1793 by Abernethy, ${ }^{1}$ which was subsequently given the term "double outlet right ventricle" by Witham in 1957.2 Double outlet right ventricle is a rare condition forming $\leqslant 1 \%$ of all congenital heart defects, and the term refers to a group of complex and heterogenous malformations that have in common only the origin of both great vessels from the right ventricle. Other cardiac malformations are always present, and frequently multiple abnormalities coexist. These may include one or more ventricular septal defects, systemic or pulmonary or left ventricular outflow obstruction, and major atrioventricular valve abnormalities.

Double outlet right ventricle may occur with any atrial situs, several different atrioventricular connections, and many other variations. Situs solitus and atrioventricular concordance are, however, the most common findings.

Cross sectional echocardiography has proved useful in the diagnosis of double outlet right ventricle. A segmental sequential approach that reliably identifies both ventricles and great vessels is mandatory. Many of the associated cardiac lesions are of paramount clinical importance and are recognisable by echocardiography. These features of diagnosis are critical in prenatal diagnosis as echocardiography is the only tool available, and further advice and obstetric management must be based on these findings.

Requests for reprints to Ms P A Stewart, Department of Obstetrics and Gynaecology, Academic Hospital Rotterdam - Dijkzigt, Erasmus University Rotterdam, Dr Molewaterplein 40, 3015 GD Rotterdam, The Netherlands.
We report the detection of double outlet right ventricle with subpulmonary ventricular septal defect and a right sided hypoplastic aorta in a 22 week old fetus of a mother with diabetes mellitus class $\mathrm{C}$, type I (White classification). ${ }^{3}$

\section{Case report}

A 21 year old gravida 1 with diabetes mellitus type $C$, who had been diabetic since the age of 13 years, underwent amniocentesis at 16 weeks' gestation, which showed a normal female karyotype. She was referred to this unit for prenatal echocardiography in view of the known association of cardiac structural abnormalities in the offspring of diabetic patients. Ultrasonic examination of the fetus was carried out at 22 weeks' gestation with a Diasonics Cardio Vue 100 mechanical sector scanner with $5 \mathrm{MHz}$ transducer. Fetal size was appropriate for gestational age. Scanning of the fetal heart showed atrioventricular concordance and a large subpulmonary ventricular septal defect. Both great vessels were connected to the right ventricle with a side by side position with the aorta, which appeared hypoplastic, to the right of the pulmonary artery (Fig. 1a). The pulmonary artery was seen to be continuous with the mitral valve. No other structural anomalies were observed in the fetus.

\section{NECROPSY FINDINGS}

The parents were informed of the findings and requested termination of the pregnancy, which was performed at 23 weeks' gestation. A female fetus weighing $400 \mathrm{~g}$ was delivered. Postmortem examination of the heart confirmed the antenatal echocardiographic findings. There was a large subpulmonary 


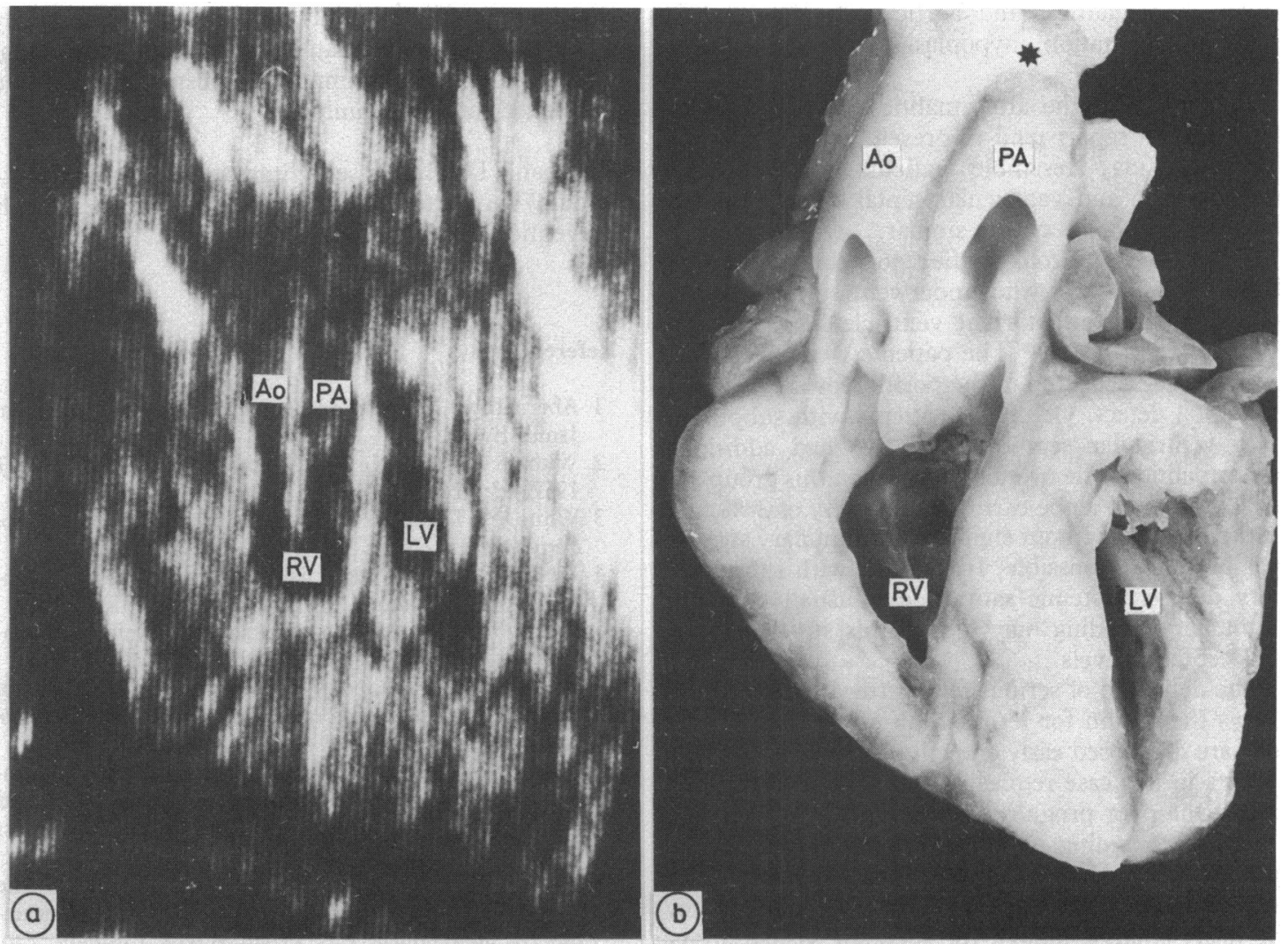

Fig. (a) Longitudinal cross sectional echocardiogram in the fetus showing both great vessels connected to the right ventricle (RV). In real time images the aorta $(A o)$ was traced to the head and neck vessels and looked hypoplastic; the pulmonary artery (PA) was also traced to its bifurcation. The ventricular septal defect was not visualised in this plane. (b) Morphological appearance of the fetal heart cut in a section equivalent to the echocardiogram in $(a)$. The outfow tract into the aorta is narrow and the ascending aorta slightly underdeveloped. There is tubular hypoplasia $\left(^{\star}\right)$ between the left subclavian and left common carotid arteries. LV, left ventricle.

perimembranous ventricular septal defect and a slitlike muscular ventricular septal defect in the inlet septum. Both great vessels were connected to the right ventricle with the aorta to the right of the pulmonary artery (Fig. 1b). There was subaortic stenosis and slight underdevelopment of the descending aorta. Tubular hypoplasia of the aortic arch was found between the left subclavian and left common carotid arteries. The pulmonary valve was in fibrous continuity with the mitral valve. No other structural anomalies were present in the fetus.

\section{Discussion}

Diabetes mellitus is known to be associated with an increased risk of fetal abnormalities, ${ }^{45}$ including skeletal, central nervous system, genitourinary, gastrointestinal, and cardiac anomalies. Cardiovascular anomalies may occur in approximately $5 \%$ of these infants. ${ }^{67}$

Amniocentesis, which in this unit is performed routinely in juvenile diabetics for alpha fetoprotein estimation and karyotyping, had been performed at 16 weeks' gestation and showed a normal concentration of alpha fetoprotein and normal female karyotype. Had this not been the policy karyotyping would have been performed after detection of the cardiac abnormalities to exclude chromosomal abnormality. The prognosis in patients with double outlet right ventricle depends on the severity of associated lesions, and the haemodynamic disturbances may be extremely variable. Clinical presentation is influenced by the presence or absence of pulmonary stenosis, the position of the ventricular septal defect in relation to the great arteries, and other associated major defects-for example, left ventricular outflow obstruction, mitral 
valve abnormalities, and aortic arch abnormalities such as coarctation, hypoplasia, or even complete interruption.

Patients with the abnormalities described in the fetus in this report tend to present early in life and, clinically, may resemble patients with complete transposition and ventricular septal defect since the haemodynamic effects are similar.

Franks and Lincoln studied 46 patients from the Brompton Hospital who underwent surgical correction of double outlet right ventricle between April 1973 and April $1981 . .^{8}$ The patients were subdivided into groups according to the position of the ventricular septal defect. Of the 12 patients with subpulmonary ventricular septal defect, five had additional abnormalities. The overall mortality in this group was $80 \%$. Palliation alone carried a mortality of $36 \%$, and in the patients without significant pulmonary stenosis was not always possible. In patients with subpulmonary defects systemic saturation is usually low and pulmonary banding may reduce this still further to unacceptable levels.

The detection of serious fetal cardiac abnormalities allows the option for termination of pregnancy ${ }^{10}$ if they are diagnosed early enough in gestation, and the parents in our case requested this option after being told of the poor prognosis.

Ideally, scanning of fetuses at risk for structural cardiac defects should be performed between 17 and 24 weeks' gestation. During this period of pregnancy the heart is large enough for adequate visualisation, and there is enough amniotic fluid surrounding the fetus to provide a good ultrasonic window. In the present case optimal imaging of the fetal heart was possible only at 22 weeks' gestation because of maternal obesity.

When congenital heart disease is diagnosed later in pregnancy or when the defect is considered amenable to surgery, or if the parents choose that the pregnancy should continue, steps can be taken to ensure optimal timing of delivery and immediate postnatal care in the paediatric cardiology unit.

We thank Dr C E Essed (Erasmus University, Rotterdam) for performing the necropsy and the Dutch Prevention Fund for funding this work.

\section{References}

1 Abernethy J. Surgical and physiological essays. London: James Evans, 1793: 163.

2 Witham AC. Double outlet right ventricle. Am Heart $\mathcal{f}$ 1957; 53: 928-39.

3 White P. Diabetes mellitus in pregnancy. Clinics in Perinatology 1974; 1: 331-47.

4 Day RE, Insley J. Maternal diabetes mellitus and congenital malformation. Arch Dis Child 1976; 51: 935-8.

5 Gabbe SG. Congenital malformations in infants of diabetic mothers. Obstet Gynecol Suro 1977; 32: 125-32.

6 Rowland TW, Hubbell JP Jr, Nadas AS. Congenital heart disease in infants of diabetic mothers. $\mathcal{F}$ Pediatr 1973; 83: 815-20.

7 Nora JJ, Nora AH. Congential heart disease: environmental factors. In: Nora JJ, Nora AH, eds. Genetics and counseling in cardiovascular diseases. Springfield, Illinois: Charles C Thomas, 1978: 147-54.

8 Franks R, Lincoln C. Surgical management of the double outlet right ventricle. In: Anderson RH, Macartney FJ, Shinebourne EA, Tynan M, eds. Paediatric cardiology Volume 5. London: Churchill Livingstone, 1983: 441-50.

9 Silverman NH, Enderlein MA, Golbus MS. Ultrasonic recognition of aortic valve atresia in utero. Am $\mathcal{f}$ Cardiol 1984; 53: 391-2.

10 Stewart PA, Tonge HM, Wladimiroff JW. Arrhythmia and structural abnormalities of the fetal heart. $\mathrm{Br} \mathrm{Heart} \mathcal{f}$ 1983; 50: $550-4$.

\section{Notice}

British Cardiac Society

The Autumn Meeting will be held at the Wembley

Conference Centre, London, on 26 to 28 November

1985 , and the closing date for receipt of abstracts was 1 August 1985.

The Annual General Meeting for 1986 will take place in York on 2 and 3 April 1986, and the closing date for receipt of abstracts will be 2 January 1986 . 